\title{
Unusual Location of a Giant Cell Tumour
}

\author{
El Mehdi Kabir, Fatiha Aghrib, Hasnaa Belgadir, Omar Amriss, Aicha Merzem, Nadia Moussali, Naima el Benna \\ Hôpital 20 Août, Casablanca, Morocco
}

Doi: 10.12890/2021_002329 - European Journal of Case Reports in Internal Medicine - ๑ EFIM 2021

Received: 26/01/2021

Accepted: 08/02/2021

Published: 01/03/2021

How to cite this article: Kabir EM, Aghrib F, Belgadir H, Amriss O, Merzem A, Moussali N, el Benna N. Unusual location of a giant cell tumour. EJCRIM 2021;8: doi:10.12890/2021_002329

Conflicts of Interests: The Authors declare that there are no competing interests.

This article is licensed under a Commons Attribution Non-Commercial 4.0 License

\section{ABSTRACT}

Giant cell tumours (GCT) are rare aggressive non-cancerous tumours which usually affect the long bones. We describe a case of GCT of the first rib in a young woman without a relevant history. The patient presented a left cervico-thoracic mass which was biopsied in our department (CT-guided biopsy). She was referred to the thoracic surgery department after histological results.

\section{LEARNING POINTS}

- Giant cell tumours (CGT) are benign tumours that usually occur on long bones with costal localization being a rare entity.

- Ultrasound can be a useful tool to assess the nature of the lesion.

- Diagnosis is based on lesion biopsy, but aggressive surgical resection can be performed.

- CGT should be considered in the differential diagnosis of costal tumours.

\section{KEYWORDS}

Giant cell tumour, costal lesion, posterior arc, unusual localization

\section{INTRODUCTION}

Giant cell tumours of the bone are rare primitive tumours mainly affecting young adults. They are frequently recurrent, often benign and located, most of the time, at the extremities of the long bones of the limbs. Costal localization is a rare entity

\section{CASE DESCRIPTION}

We report the case of 31-year-old woman with no relevant history who presented with a left cervicothoracic lesion (Fig. 1) which had gradually increased in size over the past year and was associated with moderate recurrent pain. Clinical examination showed a hard, fixed mass with an approximate diameter of $5 \mathrm{~cm}$ which was attached to the anterior chest wall. The overlying skin was normal.

A chest $x$-ray showed poorly limited opacity projecting from the posterior arch of the first left rib (Fig. 2). Ultrasound showed a heterogenous hypoechogenic posterolateral, oval shape which was poorly vascularized on Doppler (Fig. 3). Chest CT revealed an osteolytic lesion centred on the posterior arch of the first left rib, measuring $4 \times 4 \times 3 \mathrm{~cm}$ and blowing out the bone cortex which was thinned without detectable periosteal reaction (Fig. 4).

A scan-guided biopsy revealed a giant cell bone tumour on histopathological analysis. The patient presented a left cervico-thoracic mass which was biopsied in our department (CT-guided biopsy). The patient was referred to the thoracic surgery department.

\section{DISCUSSION}

Giant cell tumour (GCT) of bone is a benign bone tumour with aggressive potential, representing 5\% of all primary bone tumours. Malignant transformation is possible. The tumour is characterized by vascularized tissue made up of plump, spindle or ovoid cells in addition to numerous multinucleated giant cells uniformly dispersed throughout the tumour tissue ${ }^{[1]}$. 

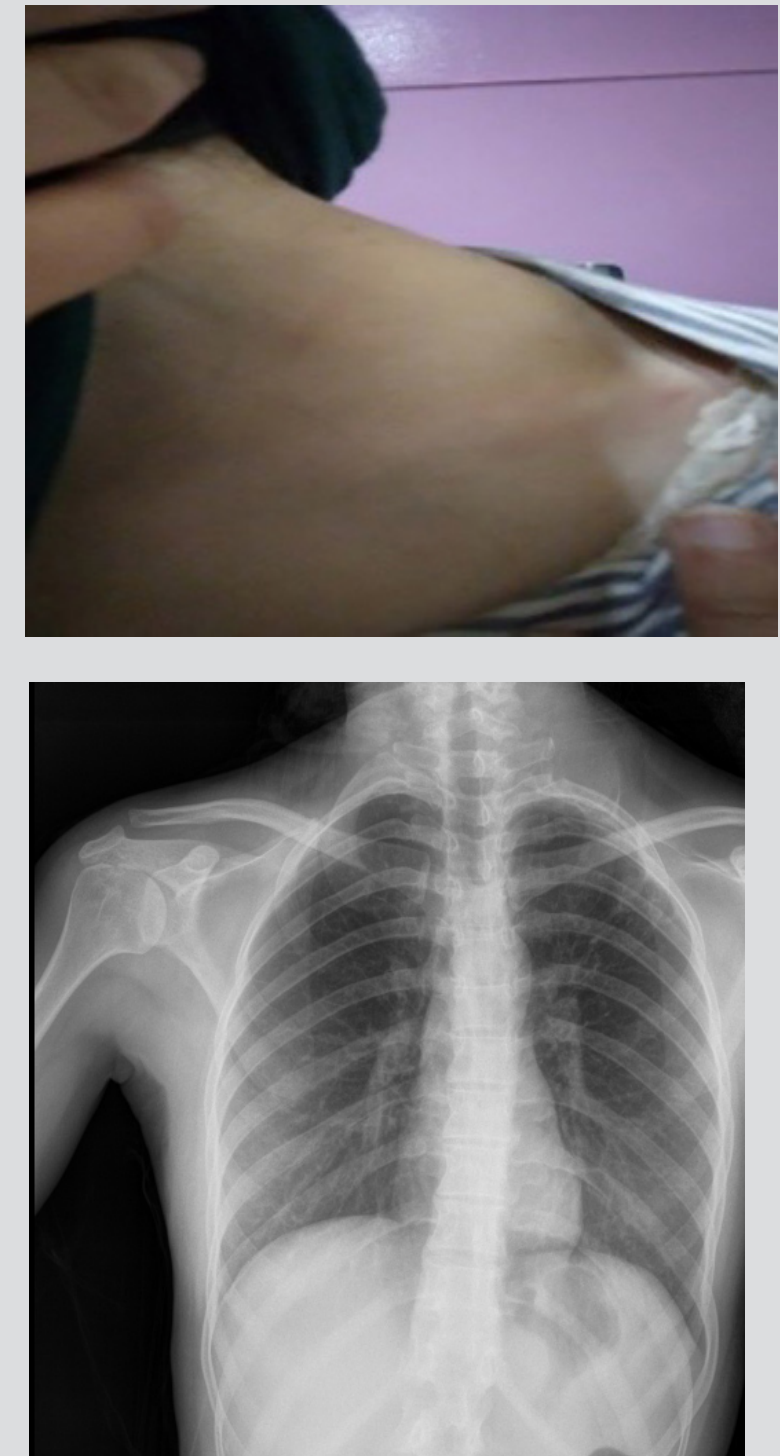

Figure 2. Chest radiography showing opacity projecting from the posterior arch of the first left rib

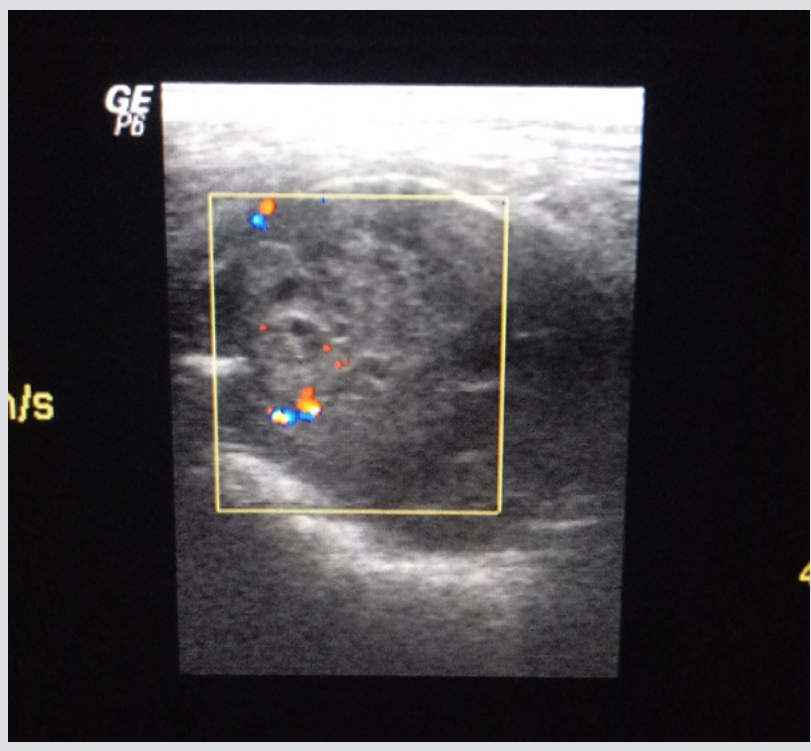

Figure 3. Ultrasound with colour Doppler demonstrates an oval hypoechoic heterogenous lesion showing poor vascularization

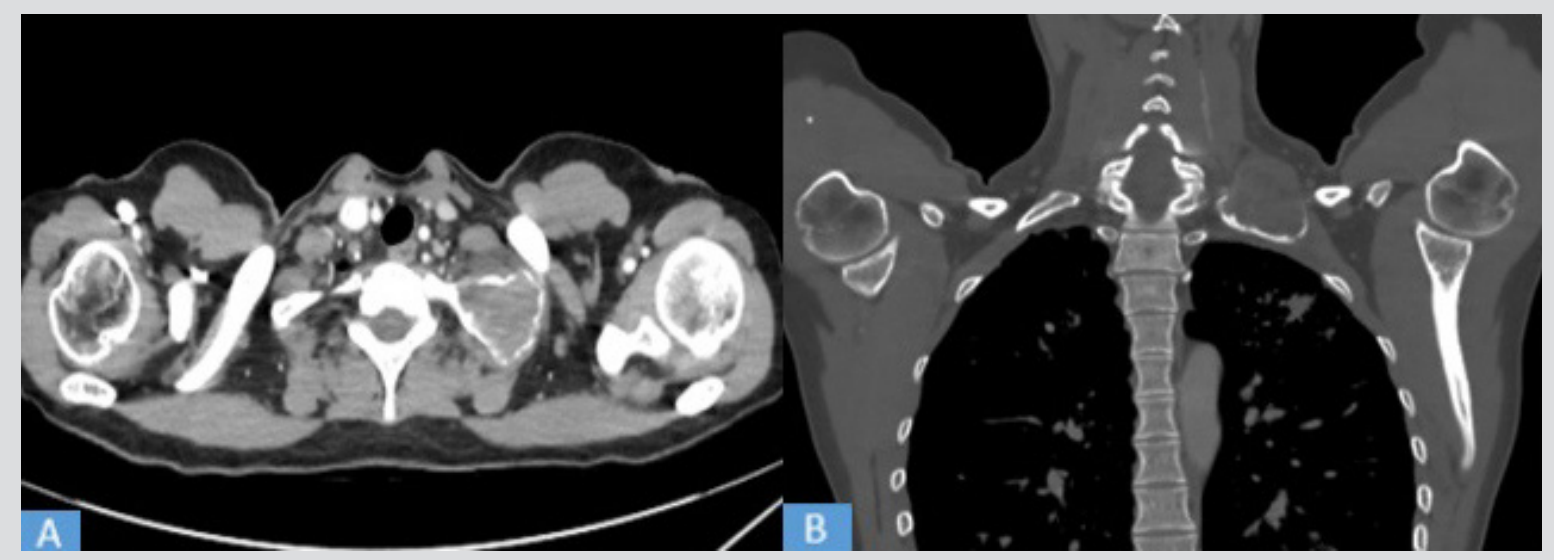

Figure 4. Computed tomography: (A) axial mediastinal window and $(B)$ coronal bone window reconstruction demonstrates a lesion with peripheral calcification; no local or regional extension was noted 
Typically, GCT affects mature bone and most commonly involves the epiphysis in adults (20-40 years of age) with women affected twice as often as men ${ }^{[2]}$, and the metaphysis in children. It has a predilection for the ends of long bone and epiphyseal portions of bone. About $60 \%$ are seen around the knee joint. Uncommon sites of GCT include the distal end of the sternum, scapula, fibula, patella, vertebrae, craniofacial bones, sacrum and ribs.

GCT rarely involves a rib (1\%) ${ }^{[3]}$, in such a case making its diagnosis challenging because of its rarity.

The clinical presentation is not specific, and patients may present with moderate pain, swelling, and/or pathological fractures. Radiographic features usually consist of an eccentric lytic lesion with no sclerotic halo. Periosteal reaction is uncommon ${ }^{[1,2]}$. MRI can be useful for analysis of the soft tissue mass.

Bone lesions are not usually evaluated with ultrasound as the sound waves are not able to penetrate the cortex. In our case, the cortex was thinned so the ultrasound could identify the osseous features of the lesion. Ultrasound can provide information about the tissue or cystic nature of the lesion and its relationship with the surrounding tissues. Ultrasound usually reveals a well-defined, oval or round, hypoechoic heterogenous lesion showing poor vascularization.

The differential diagnosis included lymphoma, chondrosarcoma and metastatic tumour.

The tumour was biopsied and a diagnosis of GCT of the rib was made on the basis of clinical, radiological and histopathological characteristics. GCT originating from the rib has been successfully treated with wide excision with negative margins and chest wall reconstruction [4]. Radiation therapy is not recommended because most malignant transformations in GCTs are associated with previous radiation therapy. Aggressive surgical extirpation is recommended even in cases with pulmonary metastasis ${ }^{[5]}$.

\section{CONCLUSION}

Our report highlights the rarity of both the reported pathology (CGT) and its costal localization. CGT should be considered in the differential diagnosis of costal tumours in the presence of a soft tissue swelling and lytic lesion in the rib. Ultrasound can identify the osseous features of the lesion, give some tissue characterization and prove a useful tool in a low resource setting.

\section{REFERENCES}

1. Dehghan A, Moaddab AH, Eskandarlou M, Moeeni A. Anterior chest wall giant cell tumor. Gen Thorac Cardiovasc Surg 2010;58:39-41.

2. Cordeiro SZB, Cordeiro PB, Sousa AMC, Lannes DC, Pierro GSM. Giant cell tumor of the rib occupying the entire hemithorax. J Bras Pneumol 2008;34(3):185-188.

Shin JS, Lee IS, Kim A, Kim BH. Giant cell tumor originating from the arc of the rib. J Korean Med Sci 2002;17:849-851.

4. Sharma A, Armstrong AE. Giant cell tumor of rib arising anteriorly as a large inframammary mass: a case report and review of the literature. Case Rep Med 2012;2012:850509.

5. Takanami I, Takeuchi K, Naruke M, Kodaira S. Aggressive surgery for treating a pulmonary metastasis of a benign giant cell tumor of the bone: results in four cases. $J$ Thorac Cardiovasc Surg 1998;116:649-651. 